\title{
Novel Trend in Colon Cancer Therapy Using Silver Nanoparticles Synthesized by Honey Bee
}

\section{Nehal M El-Deeb ${ }^{1}$, Ibrahim M El-Sherbiny ${ }^{2 *}$, Mohamed R El-Aassara ${ }^{3}$ and Elsayed E Hafez ${ }^{4}$}

${ }^{1}$ Biopharmaceutical Product Research Department, Genetic Engineering and Biotech. Institute, City of Scientific Research and Technology Applications, New Borg El-Arab City 21934, Alexandria, Egypt

${ }^{2}$ Zewail City of Science and Technology, Center for Materials Science, 6th October City, 12588 Giza, Egypt

${ }^{3}$ Polymer Materials Research Department, Institute of Advanced Technology and New Materials, City of Scientific Research and Technology Applications, New Borg El-Arab City 21934, Alexandria, Egypt

${ }^{4}$ Plant Protection and Biomolecular Diagnosis Department, Arid Lands Cultivation Research Institute, City of Scientific Research and Technology Applications, New Borg El-Arab City 21934, Alexandria, Egypt

\begin{abstract}
Recently, the biosynthesis of nanoparticles has been well explored which draws attention to its possible biomedical applications especially in cancer therapy. In the current study, the novelty in the biosynthesis of silver nanoparticles (AgNPs) using honey bee extract has been explained. This study was also aiming at investigating the anti-colon cancer activities of the biogenic AgNPs along with its capping biomolecules in vitro. The obtained biogenic AgNPs were well characterized by X-ray diffraction (XRD), energy dispersive X-ray (EDX), scanning electron microscopy (SEM), and transmission electron microscopy (TEM). It was found that the formed AgNPs have spherical shape with size range from 12 to $18 \mathrm{~nm}$ embedded in honey bee biomolecules. The cytotoxicity results of AgNPs on peripheral blood mononuclear cells (PBMC) indicated that the obtained AgNPs could be used safely with concentrations upto $39 \mu \mathrm{g} / \mathrm{ml}$. On the other hand, the potentialities of the biogenic AgNPs against colon cancer proliferation recorded $60 \%$ inhibition using its nontoxic dose with a down regulation of the expression of $\mathrm{Bcl} 2$ and survivin gene. By the extraction of AgNPs capping biomolecules to explain the exact fraction that is responsible for the anticancer properties, it was found that both AgNPs and its capping biomolecules have anti-proliferative effects with a priority to the naked AgNPs.
\end{abstract}

Keywords: Colon cancer; Biogenic AgNPs; Survivin; BCl2; Honey bee

\section{Introduction}

Nanomedicine refers to the use of precision-engineered nanomaterials in order to reveal novel therapeutic and diagnostic tools for human use [1]. The collaboration between nanotechnology and nanomedicine resulted in the emergence of new trend in both therapeutic and pharmaceutical fields [2]. The growing need to develop environmentally benign nanotechnology using microbes and nanomaterial has received great attention in the last few years [3]. Recent reports [3-5] recorded the use of coriander leaf, henna leaf and edible mushroom in the biosynthesis of $\mathrm{Au}$ and $\mathrm{Ag}$ nanoparticles. Also, Mendoza-Reséndez [6] described the eco-friendly synthesis of AgNPs mediated by various bee products (raw honey, royal jelly, honeydew honey and propolis). Nowadays, silver nanoparticles (AgNPs) have a wide spread of applications and the highest level of commercialization among the nanomaterials [7]. For instance, among different nanoparticles investigated, AgNPs are the most promising particles that are used in the field of nanomedicine for their antimicrobial activity against different microbes [1]. However, there is serious lack of sufficient information concerning the biological effects of AgNPs on human cells. In addition, there are limited studies on the potential of biogenic AgNPs as anticancer agents. Among these studies, there is a recent report on the anti-proliferative activities of AgNPs against human glioblastoma cells (U251) [2]. Besides, Yezhelyev et al. [8] revealed that AgNPs in the size range 1-1000 nm could be very beneficial for the diagnosis and treatment of cancers which may lead to the new discipline of nano-oncology. Due to the lack of efficiency in many of the available synthetic anticancer drugs, such as doxorubicin, cisplatin, and bleomycin, it is important to find novel therapeutic agents [9]. This report introduces a simple, cost-effective and environmentally benign synthesis of AgNPs using honey bee. In addition, the activity of the synthesized AgNPs against human epithelial colorectaladeno carcinoma was evaluated with also referring to its molecular action on cellular gene expressions.

\section{Materials and Methods}

\section{Materials}

Silver nitrate $\left(\mathrm{AgNO}_{3}\right)$ was purchased from Sigma-Aldrich. Cell culture media was provided by Lonza. Other chemicals were of analytical grade and used without any further purification.

\section{Green synthesis of AgNPs using honey bees extract}

About 50 mature honey bee workers were collected from honey bee colony (SRTA-City Farm), sterilized with $0.05 \%$ Clorox solution, and then washed three times with sterile $\mathrm{H}_{2} \mathrm{O}$. The insects were left to dry on a pre-sterilized laminar flow. The insects were then ground in a clean and sterile motor with sterile phosphate buffer (PBS; $\mathrm{pH}=7$, $25 \mathrm{mM})$. Afterwards, the extract was filtrated through three layers of sterilized muslin and each $100 \mathrm{ml}$ of filtrate was transferred into a sterile $250 \mathrm{ml}$ flask. As a substrate for AgNPs production, $\mathrm{AgNO}_{3}$ was added to the insects filtrate with final concentration of $1 \mathrm{mM}$ in the presence of glucose $(560 \mathrm{Mm})$ as electron donor. The mixture was

*Corresponding author: Ibrahim M El-Sherbiny, Zewail City of Science and Technology, Center for Materials Science, 6th October City, 12588 Giza, Egypt Tel: 2-0106-333-0913; E-mail: ielsherbiny@zewailcity.edu.eg

Received December 02, 2014; Accepted January 22, 2015; Published February 02, 2015

Citation: El-Deeb NM, El-Sherbiny IM, El-Aassara MR, Hafez EE (2015) Novel Trend in Colon Cancer Therapy Using Silver Nanoparticles Synthesized by Honey Bee. J Nanomed Nanotechnol 6: 265. doi:10.4172/2157-7439.1000265

Copyright: (c) 2015 El-Deeb NM, et al. This is an open-access article distributed under the terms of the Creative Commons Attribution License, which permits unrestricted use, distribution, and reproduction in any medium, provided the original author and source are credited. 
incubated with shaking $(220 \mathrm{rpm})$ at room temperature. At different time intervals, samples of $1.5 \mathrm{ml}$ were taken from the reaction mixture and the absorbance of the resulting colloidal suspension of AgNPs was recorded immediately against the experimental blank at $450 \mathrm{~nm}$ with the aid of Shimadzu UV-vis spectrophotometer. The collection of the produced AgNPs was achieved by centrifugation at 10,000 rpm for 20 min followed by dissolving the formed pellet in $0.1 \mathrm{ml}$ of $25 \mathrm{mM}$ PBS at $\mathrm{pH}=7$, and stored at $4^{\circ} \mathrm{C}$ until being used.

\section{Characterization of the synthesized AgNPs}

The morphology of AgNPs was analyzed using scanning electron microscopy (JEOL SEM, GSM-6610LV, Japan) at an accelerated voltage of $15 \mathrm{kV}$. The samples surfaces were vacuum coated with gold for SEM. Dimensional analysis and structural characterization of the obtained AgNPs were carried out by transmission electron microscopy (TEM) using high-resolution JEOL 2100-TEM, Japan operated at $200 \mathrm{kV}$, and with the aid of X-ray diffraction (Shimadzu XRD 7000 $\mathrm{X}$-ray diffractometer, Japan) using a DRON 2.0 diffractometer with $\mathrm{Cu}$ tube (Ka radiation).

\section{Cytotoxicity assay of the biogenic AgNPs on cell lines}

Cell culture: $\mathrm{CaCO}_{2}$ (human epithelial colorectaladeno carcinoma, American Type Culture Collection, ATCC; Manassas, VA, USA) were washed twice with DMEM media (Lonza) supplemented with $200 \mu \mathrm{M}$ L-glutamine and $25 \mu \mathrm{M}$ HEPES buffer (all chemicals and media were Cambrex). $2 \times 10^{5}$ cells were suspended in DMEM culture media with $10 \%$ fetal bovine serum (Gibco-BRL). The cells were left to adhere on the polystyrene 6 well plates for $4 \mathrm{~h}$ in an incubator $\left(37^{\circ} \mathrm{C}, 5 \% \mathrm{CO}_{2}, 95 \%\right.$ humidity). The cells were washed twice from debris and dead cells by using RPM1 supplemented media.

Human blood lymphocytes separation: Peripheral blood cells mononuclear cells (PBMCs) were isolated by gradient centrifugation as reported by Lohr et al. [10]. Briefly, peripheral blood samples were diluted with 5 volumes of freshly prepared RBC lysis buffer (38.8 $\mathrm{mmol} / \mathrm{L} \mathrm{NH}_{4} \mathrm{Cl}, 2.5 \mathrm{mmol} / \mathrm{L} \mathrm{K}_{2} \mathrm{HCO}_{3}, 1 \mathrm{mmol} / \mathrm{L}$ EDTA, $\mathrm{pH} 8.0$ ), incubated at room temperature for $10 \mathrm{~min}$, and then centrifuged at $1500 \mathrm{rpm}$ for $5 \mathrm{~min}$. The nucleated cells were precipitated at the bottom of the tube.

Cytotoxicity and proliferation assays: The safe dose of the biogenic AgNPs was determined on PBMC as normal cell model according to the methods described by Borenfreund and Puerner [11]. Briefly, $6 \times 10^{4} \mathrm{cell} / \mathrm{ml}$ was seeded in 96 -well plates and incubated under $5 \% \mathrm{CO}_{2}$ at $37^{\circ} \mathrm{C}$ till semi-confluences. After incubation, about $100 \mu \mathrm{l}$ of different AgNPs concentrations was added. After 3 days of incubation, both dead and living cells were treated with $100 \mu \mathrm{l}$ of neutral red stain solution $(100 \mu \mathrm{g} / \mathrm{ml})$. Neutral red stained only the living cells via stain incorporation into liposomes providing a quantitative assay. The stain intensity was quantified using automated ELIZA microplate reader adjusted at $540 \mathrm{~nm}$.

Assessment of antiproliferative activity: The antiproliferative activity of the biogenic AgNPs on $\mathrm{CaCO}_{2}$ cell was confirmed using trypan blue assay. The dye exclusion test is used to determine the number of viable cells present in a cell suspension. Besides, the trypan blue stain is considered as a simple way to evaluate cell membrane integrity and thus assesses cell proliferation or death. Briefly, $\mathrm{CaCO}_{2}$ cells were treated either with the non toxic doses of 5-Fluorouracil (5 FU, $0.9 \mu \mathrm{g} / \mathrm{ml})$ or the biogenic AgNPs $(39 \mu \mathrm{g} / \mathrm{ml})$ for $48 \mathrm{hrs}$. At the end of incubation, the suspensions of treated cells were simply mixed with dye and then visually examined to determine whether cells take up or exclude dye with reference to untreated cells, as a control. In the protocol presented here, viable cells will have clear cytoplasm whereas dead cells will have a blue cytoplasm.

The anticancer signals of the biogenic AgNPs: Mechanisms of target gene regulation: The anticancer activity profile of the synthesized biogenic AgNPs was explained by studying their activity in controlling the expression of $\mathrm{p} 53, \mathrm{Bcl} 2$, caspase 3 and survivin genes in $\mathrm{CaCO}_{2}$ cells. $\mathrm{CaCO}_{2}$ cells were cultured in 12 well plates $\left(6 \times 10^{3}\right.$ cell $\left./ \mathrm{ml}\right)$ for 2 days with the recorded non-toxic concentration of either biogenic AgNPs or 5FU (as a positive control). After incubation, total cellular RNA was extracted and subjected to RT-q PCR for genes expression quantification after and before treatment. Oligo-dT primer and the AMV reverse transcriptase (Promega Corp., Madison,WI)were used to synthesize the first-strand cDNA. GAPDH was used as internal control for standardization of PCR product [12]. The RT-PCR was done to the cDNA based on the SYBR Green dye (QuantiTect SYBR Green PCR Kits) and Light Cycler fluorimeter (BIO RAD S1000 ${ }^{\mathrm{Tm}}$ thermal cycler) (Table 1).

Extraction and identification of the biomolecules capping the AgNPs: Briefly, the possible biomolecules responsible for capping of the synthesized AgNPs were extracted with 3 volumes of absolute ethanol 3 times in succession. The extraction process was continued overnight at $4^{\circ} \mathrm{C}$. Then, the formed pellet was obtained via centrifugation at 40,000 rpm for $10 \mathrm{~min}$. The phosphate buffer solution (PBS)-washed pellet was then subjected to FTIR analysis for identification, in comparing with that of the complete particles.

The possible anticancer activities of the bio-synthesized AgNPs and its capping biomolecules: From a suspension of biogenic AgNPs at concentration of $39 \mu \mathrm{g} / \mathrm{ml}$, both of AgNPs and their capping biomolecules were separated from each other by ethanol precipitation as previously mentioned. Semi confluent layer of $\mathrm{CaCO}_{2}$ cells were treated for $48 \mathrm{hrs}$, with $100 \mu \mathrm{l}$ of either AgNPs or the capping biomolecules. At the end of incubation, cellular viability was checked using trypan blue dye as previously described.

\section{Results and Discussion}

\section{UV-Vis spectral analysis of the synthesized AgNPs}

The formation of the AgNPs was confirmed through the color change in the reaction mixture $\left(\mathrm{AgNO}_{3}\right.$ solution + honey bee extract $)$ which is due to the reduction of the $\mathrm{Ag}^{+}$ions into $\mathrm{Ag}$ atoms then into nanoparticles. Besides, as mentioned previously in the method section, the absorbance of AgNPs colloidal suspension was detected at $450 \mathrm{~nm}$.

\begin{tabular}{|c|c|c|c|c|c|}
\hline Primers & \multicolumn{5}{|c|}{ Sequence } \\
\hline Bcl2-forward & \multicolumn{5}{|c|}{ 5'-TATAAGCTGTCGCAGAGGGGCTA3' } \\
\hline Bcl2-reverse & \multicolumn{5}{|c|}{ 5'-GTACTCAGTCATCCACAGGGCGAT3' } \\
\hline P53-forward & \multicolumn{5}{|c|}{ 5'-AACGGTACTCCGCCACC-3' } \\
\hline P53-reverse & \multicolumn{5}{|c|}{ 5'-CGTGTCACCGTCGTGGA-3' } \\
\hline Caspase-3-forward & \multicolumn{5}{|c|}{ 5'-TGCGCTGCTCTGCCTTCT-3' } \\
\hline Caspase-3-reverse & \multicolumn{5}{|c|}{ 5'-CCATGGGTAGCAGCTCCTTC-3' } \\
\hline Survivin-forward & \multicolumn{5}{|c|}{ 5'-TGCCCCGACGTTGCC-3 } \\
\hline Survivin-reverse & \multicolumn{5}{|c|}{ 5'-CAGTTCTTGAATGTAGAGATGCGGT-3' } \\
\hline GAPDH-forward & \multicolumn{5}{|c|}{ 5'-GAA GGT GAA GGT CGG AGT } \\
\hline GAPDH-reverse & \multicolumn{5}{|c|}{ 3'-GAA GAT GGT GAT GGG ATT TC } \\
\hline \multicolumn{6}{|c|}{ Table 1: List of primers. } \\
\hline & Day 1 & Day 2 & Day 3 & Day 4 & Day 5 \\
\hline OD (450 nm) & 0.561 & 0.822 & 0.856 & 0.896 & 0.891 \\
\hline
\end{tabular}

Table 2: UV-Vis spectral analysis of the biosynthesis of AgNPs. 
This absorption is attributed to the surface plasmon resonance (SPR) of the nanoparticles. The UV-vis absorption corresponding to the bioreduction of the $\mathrm{Ag}^{+}$ions in aqueous solution occurred at different time intervals is shown in Table 2. The results revealed that the reduction reaction progressed spontaneously with incubation time but this biosynthesis process of AgNPs was almost completed after four days.

\section{Chemical and physical analysis of AgNPs}

A scanning electron micrograph as well as the EDX analysis results of the AgNPs prepared from honey bee are shown in Figure 1I. It is apparent from the figure that the AgNPs obtained with raw honey bee extract are spherical. Elemental analysis of the AgNPs prepared by honey bee was carried out using SEM-EDX as also appeared in Figure 1II. The results showed that carbon, oxygen, and Ag were the principal elements of the resulting AgNPs. The EDX quantitative analysis confirms the nanostructure of the AgNPs which contains about 19.85 wt $\%$ Ag, $45.22 \mathrm{wt} \%$ carbon, and about $34.93 \mathrm{wt} \%$ of oxygen.

Figure 2 illustrates the XR diffractogram of the biosynthesized AgNPs. From the figure, the crystalline nature of the AgNPs was confirmed as elemental Ag (0). Besides, the calculation revealed that the size of the obtained AgNPs ranged from 20 to $60 \mathrm{~nm}$. The diffraction peaks appeared at about $32.3^{\circ}, 46.6^{\circ}$, and $76.8^{\circ}$ are corresponding to the planes; (111), (200) and (311), respectively.

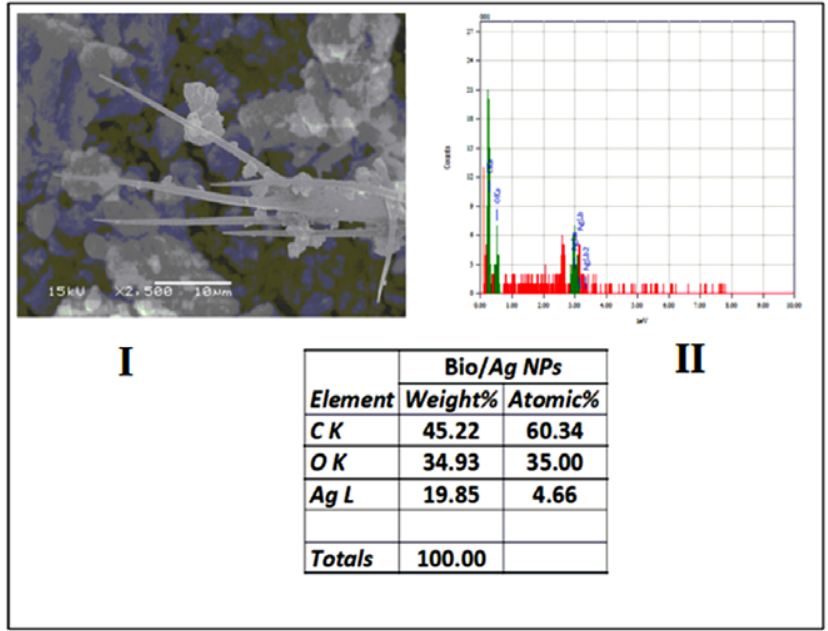

Figure 1: (I) SEM image, and (II) the elemental distribution and stoichiometric ratios of AgNPs/ honey bee as determined by EDS.

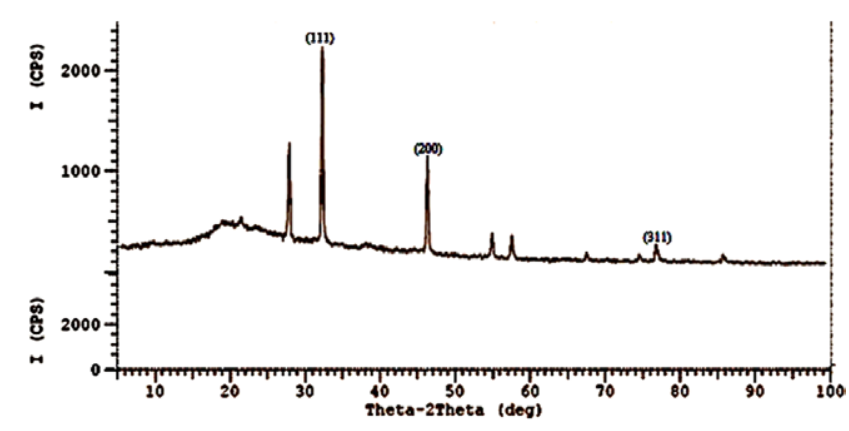

Figure 2: XR diffractogram of dried powder of AgNPs.

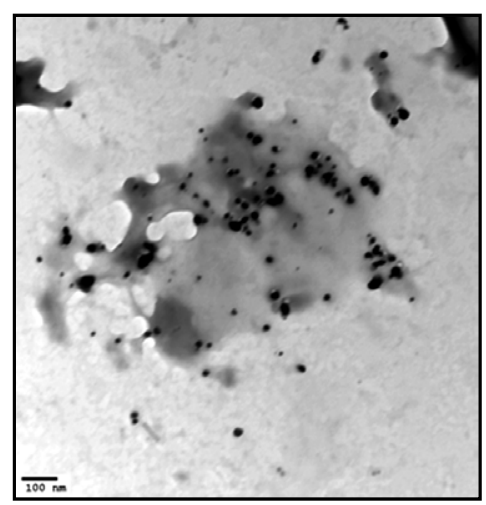

Figure 3: TEM micrographs of the AgNPs capped with the honey bee biomolecules.

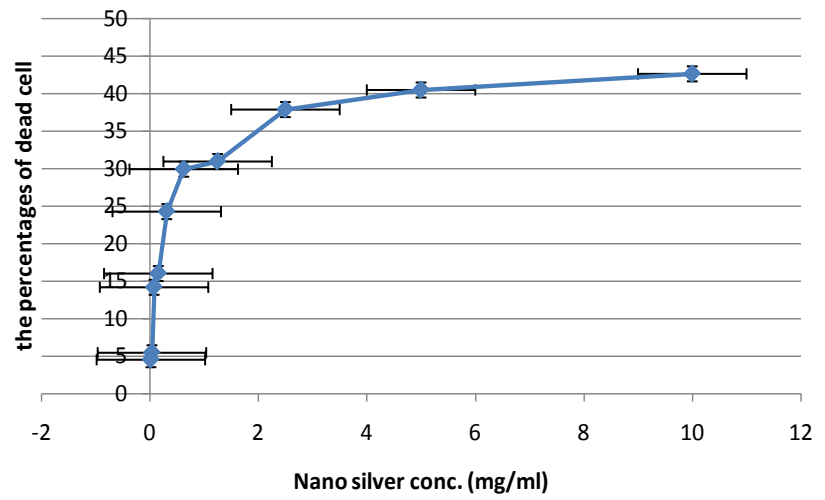

Figure 4: Cytotoxicity assay of the developed biogenic AgNPs on peripheral blood mononuclear cells.

The surface morphology of the developed AgNPs has been investigated using TEM as illustrated in Figure 3. From the figure, the AgNPs are dense and spherical with a size range between 12 and $18 \mathrm{~nm}$. The TEM micrograph also demonstrates that the obtained AgNPs are embedded on the honey bee biomolecules.

\section{Cytotoxicity assay of the biogenic AgNPs}

Cytotoxicity test on PBMC was chosen as a reference to the treatments safety on normal cells. The cytotoxicity results shown in Figure 4 indicated that the recommended dose of the biogenic AgNPs is $39 \mu \mathrm{g} / \mathrm{ml}$ with a cellular viability inhibition percentage of 5.453 . On the other hand, the non toxic dose of 5-Fluorouracil (5 FU), as the positive control has reached up to $0.9 \mu \mathrm{g} / \mathrm{ml}$ with inhibition percentage of 10.9 (Data is not shown). The comparison between the toxicity of the developed biogenic AgNPs and that of the standard anticancer drug, 5 FU proved that the biogenic AgNPs were safer on the PBMC.

\section{Assessment of the antiproliferative activity}

The results of antiproliferative activity of the biogenic AgNPs on $\mathrm{CaCO}_{2}$ cells are shown in Figure 5. The results indicated that, at the end of AgNPs incubation with $\mathrm{CaCO}_{2}$ cells, the inhibition of cellular viability reached up to $60 \%$ compared with $66.68 \%$ in the case of the cells treated with $5 \mathrm{FU}$. 


\begin{tabular}{|c|c|c|c|c|c|c|c|}
\hline Target & Sample & Mean Cq & $\begin{array}{l}\text { Mean Efficiency } \\
\text { Corrected Cq }\end{array}$ & $\begin{array}{l}\text { Normalized } \\
\text { Expression }\end{array}$ & $\begin{array}{c}\text { Relative } \\
\text { Normalized } \\
\text { Expression }\end{array}$ & Regulation & $\begin{array}{l}\text { Compared to } \\
\text { Regulation } \\
\text { Threshold }\end{array}$ \\
\hline bcl2 & $5 \mathrm{Fu}$ & 29.36 & 29.36 & 1.61248 & 0.07412 & 13.49113- & Down regulated \\
\hline $\mathrm{bcl} 2$ & (-ve) Control & 28.86 & 28.86 & 21.75417 & 1 & 1 & No change \\
\hline bcl2 & AgNPs & 32.44 & 32.44 & 0.46529 & 0.02139 & $46.75447-$ & Down regulated \\
\hline caspase 3 & $5 \mathrm{Fu}$ & N/A & N/A & N/A & N/A & N/A & No change \\
\hline caspase 3 & (-ve) Control & $\mathrm{N} / \mathrm{A}$ & $\mathrm{N} / \mathrm{A}$ & $\mathrm{N} / \mathrm{A}$ & $\mathrm{N} / \mathrm{A}$ & $\mathrm{N} / \mathrm{A}$ & No change \\
\hline caspase 3 & AgNPs & $\mathrm{N} / \mathrm{A}$ & $\mathrm{N} / \mathrm{A}$ & $\mathrm{N} / \mathrm{A}$ & $\mathrm{N} / \mathrm{A}$ & $\mathrm{N} / \mathrm{A}$ & No change \\
\hline GAPDH & $5 \mathrm{Fu}$ & 30.05 & 30.05 & $\mathrm{~N} / \mathrm{A}$ & $\mathrm{N} / \mathrm{A}$ & $\mathrm{N} / \mathrm{A}$ & No change \\
\hline GAPDH & Control & 33.3 & 33.3 & $\mathrm{~N} / \mathrm{A}$ & $\mathrm{N} / \mathrm{A}$ & $\mathrm{N} / \mathrm{A}$ & No change \\
\hline GAPDH & AgNPs & 31.34 & 31.34 & $\mathrm{~N} / \mathrm{A}$ & $\mathrm{N} / \mathrm{A}$ & $\mathrm{N} / \mathrm{A}$ & No change \\
\hline p53 & $5 \mathrm{Fu}$ & 23.51 & 23.51 & 93.18246 & 2.04442 & 2.04442 & No change \\
\hline p53 & (-ve) Control & 27.79 & 27.79 & 45.57886 & 1 & 1 & No change \\
\hline p53 & AgNPs & 27.36 & 27.36 & 15.80025 & 0.34666 & $2.88469-$ & No change \\
\hline Survivin & $5 \mathrm{Fu}$ & 27.53 & 27.53 & 5.75725 & 0.03707 & $26.97446-$ & Down regulated \\
\hline Survivin & (-ve) Control & 26.02 & 26.02 & 155.2988 & 1 & 1 & No change \\
\hline Survivin & AgNPs & 34.17 & 34.17 & 0.14034 & 0.0009 & 1106.62206- & Down regulated \\
\hline
\end{tabular}

Table 3: Gene expression regulation via the biogenic AgNPs treatment.

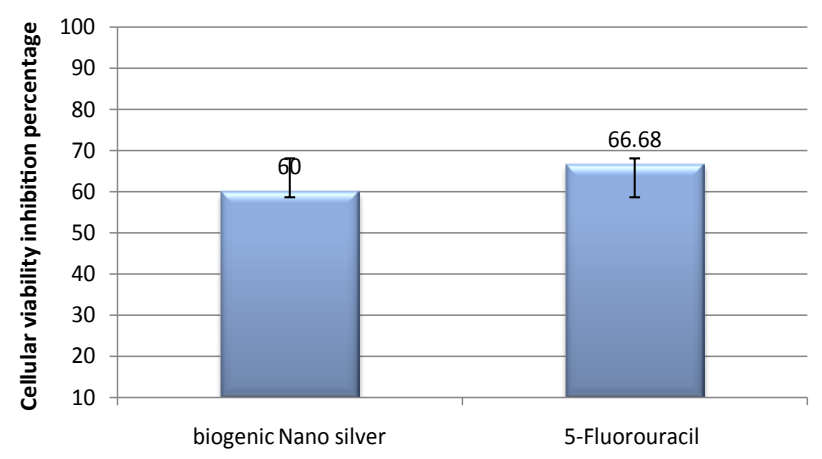

AgNPS concentration $39 \mu \mathrm{g} / \mathrm{ml} \quad$ Treatment

Figure 5: Antiproliferative activity of the biogenic AgNPs on $\mathrm{CaCO}_{2}$ cell.

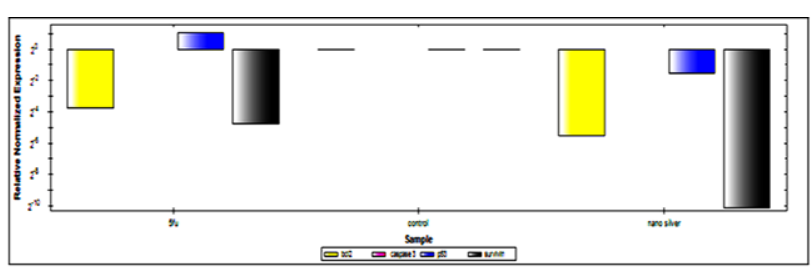

Figure 6: Gene expression regulation via the biogenic AgNPs treatment.

\section{The mechanisms of gene regulation targeted by the biogenic AgNPs}

The possible mechanisms of AgNPs-mediated cell death via the apoptotic regulators have been measured via gene expression patterns. In order to investigate the apoptotic pathway, RNA levels of Bcl2, survivin and caspase 3 were quantitatively measured through RT-PCR with GAPDH expression normalization as shown in Figure 6. The expression of the used genes upon AgNPs treatment was also compared with the standard anticancer drug, $5 \mathrm{FU}$. The overall results indicated that AgNPs treatment could induce cellular apoptosis in human epithelial colorectaladeno carcinoma cells via down regulation of the expression of both survivin and bcl2 genes without affecting the expression of caspase 3 gene. Also, treatment with $5 \mathrm{FU}$ down regulates the expression of both $\mathrm{Bcl} 2$ and survivin gene but with regulatory values smaller than that with AgNPs treatment (Table 3).

\section{FTIR analysis of the AgNPs capping biomolecules}

FTIR spectrum of the AgNPs extracted capping biomolecules is shown in Figure 7a. The frequencies for the pristine biomolecules are indicated as follows: $3446 \mathrm{~cm}^{-1}$ due to the $\mathrm{NH}$ group stretching vibration, $1097 \mathrm{~cm}^{-1}$ and $854 \mathrm{~cm}^{-1}$ are due to the $\mathrm{C}-\mathrm{O}-\mathrm{C}$ asymmetric stretching and bending vibrations, respectively. The bands at 2467 $\mathrm{cm}^{-1}$ and at $841 \mathrm{~cm}^{-1}$ are attributed to the hydrogen-bonded $\mathrm{OH}$ stretching vibrations. On the other hand, as shown in Figure 7b, the FTIR spectrum of AgNPs with its capped biomolecules indicated the presence of large amount of carbohydrates as seen by the large peak at $3510 \mathrm{~cm}^{-1}$, the $\mathrm{N}-\mathrm{H}$ stretch band merges with this hydroxyl peak. The strong absorption peaks at $2890 \mathrm{~cm}^{-1}$ can be assigned to associate with the stretching vibration of $\mathrm{C}-\mathrm{H}$, and the strong absorption peaks were observed around $1652-1656 \mathrm{~cm}^{-1}$, representing the stretching vibration of $\mathrm{C}=\mathrm{O}$ and carboxyl group, the band at $1423 \mathrm{~cm}^{-1}$, indicative of $\mathrm{C}=\mathrm{C}$ stretching, (corresponding to carbohydrates linked with AgNPs). Further evidence of linking carbohydrates with AgNPs absorbance at $2165 \mathrm{~cm}^{-1}$ which is an indicative of $-\mathrm{C} \equiv \mathrm{C}$ - stretching present in carbohydrates.

\section{Anticancer activities of the AgNPs and their capping biomolecules}

In order to detect which part of the biogenic AgNPs responsible for the anti-proliferative activity against $\mathrm{CaCO}_{2}$ cells, the anticancer activities of both AgNPs and their capping biomolecules were tested as shown in Figure 8. The figure demonstrates that both AgNPs and their capping biomolecules showed anti-proliferative effects against colon cancer superior to the naked AgNPs that showed 58.6\% inhibition. On the other hand, the green synthesized AgNPs with their capping biomolecules showed $60 \%$ inhibition, while the capping biomolecules showed $57.08 \%$ inhibition.

The green and eco-friendly approach for the synthesis of AgNPs is simple, amenable for large scale commercial production and pharmaceutical applications. Since ancient times, honey and other bee products have been widely used as therapeutic agents due to the unique health benefits they are providing which include, for instance, being antibacterial, antioxidant, antitumor, anti-inflammatory and 

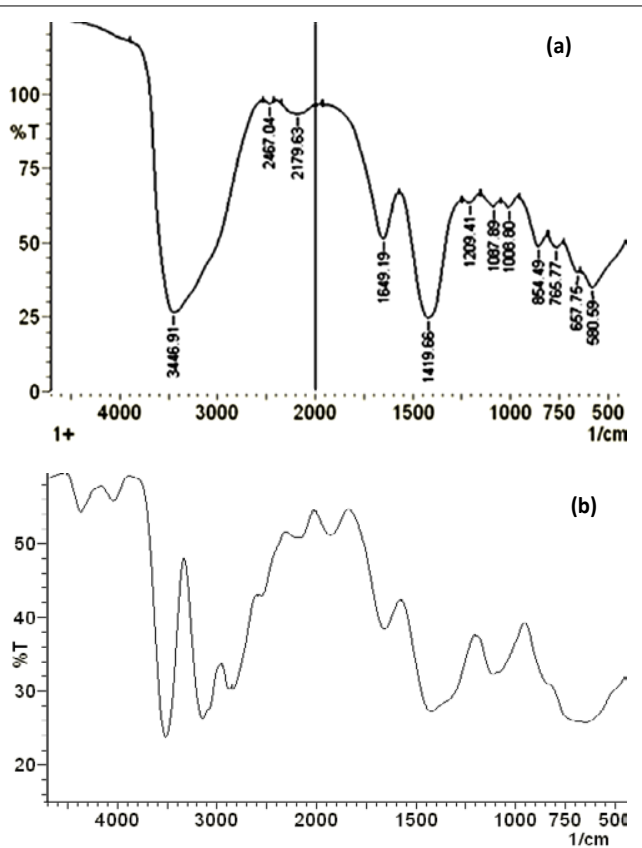

Figure 7: FTIR spectra of AgNPs (a) after extraction of capped biomolecules, and (b) with its capped biomolecules.

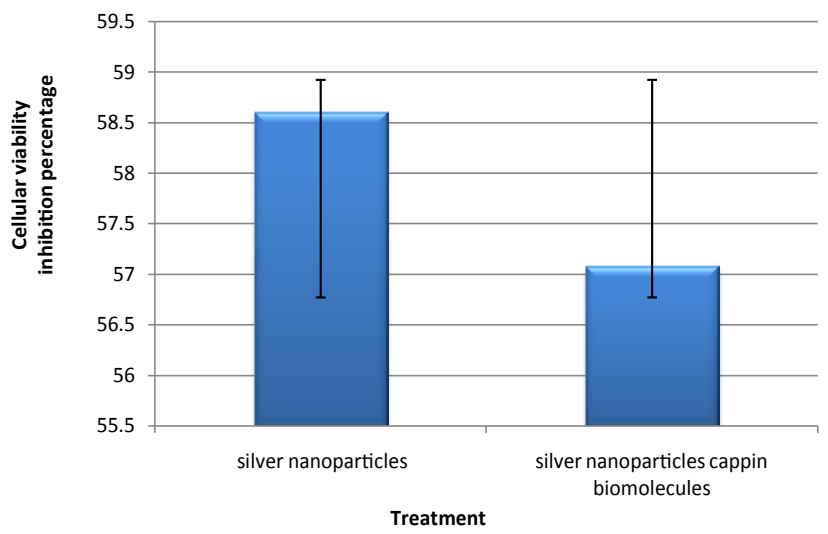

Figure 8: The anticancer activities of AgNPs and their capping biomolecules.

antiviral [13]. In the current study, bio-synthesis of AgNPs using honey bee workers was carried out rapidly and completed within few days with particle size range between 12-18 nm. EDX analysis provided direct evidence that Ag ions were embedded in the honey bee biomolecules and were well prepared without any chemical and structural modifications into the honey bee biomolecules. In addition, using XRD, the diffraction peaks appearing at $32.3^{\circ}, 46.6^{\circ}$, and $76.8^{\circ}$ correspond to the (111), (200), and (311) facets of the face centered cubic crystal structure, respectively $[14,15]$. The exact mechanism for the green synthesis of the nanoparticles still unknown. However, some recent studies have shown that biomolecules such as proteins, phenols and flavonoids present in the bio-systems play an important role in the reduction of metal ions and capping of the resulting nanoparticles [16]. Based on these reports and on parallel with Murugaraj [17] and the current results, we could clearly conclude that, part from honey bee biomolecules (may be proteins or polysaccharides) was bound with the AgNPs via free amino groups and/or carboxylic residues. These biomolecules were responsible for not only the reduction of $\mathrm{Ag}+$ into $\mathrm{Ag}^{\circ}$ but also, they acted as stabilizing capping agents to $\mathrm{Ag}^{\circ}$ and could also enhance the biological properties of the formed AgNPs. It was noticed that, mostly, the amino groups are the key agents in $\mathrm{Ag}^{+}$ions reduction and strongly adsorbed to them. In addition, the SEM micrographs confirmed the stability and the lower agglomeration tendency of the formed AgNPs due to the presence of these biomolecules.

Because the biomolecules interaction with noble metals may be helpful in cell biology and medicine [18], biogenic nanoparticles could be used as alternative or complementary agents in cancer treatment. In this study, the non-toxic dose of AgNPs on PBMC reached $39 \mu \mathrm{g} / \mathrm{ml}$. This dose recorded $60 \%$ inhibition on $\mathrm{CaCo} 2$ cell proliferation. This data is specified particularly to $\mathrm{CaCO}_{2}$ cells. Concerning other types of human cancer cells such as MCF7, they showed $100 \%$ cell death by treating with $50 \mu \mathrm{g} / \mathrm{ml}$ concentrations of the AgNPs [18]. Contrariwise, the mushroom obtained AgNPs showed sever cytotoxic effects against MDA-MB-231 cell lines at comparatively low concentration of $6 \mu \mathrm{g} / \mathrm{ml}$ [19]. Based on these findings, it is here envisaged that the cytotoxicity of nanoparticles is relied much on the cell types and nanoparticle size $[19,20]$. Cellular uptake of nanoparticles leads to generation of reactive oxygen species which provoke oxidative stress. In cells, inorganic nanoparticles easily cross the nuclear membrane and profoundly interact with intracellular macromolecules like proteins and DNA. The mechanism of nanoparticles interaction with DNA is still unknown [21]. Apoptosis-inducing agents that specifically target the tumour cells via gene expression regulation might have the potential to be developed as new anti-tumour agents without induction of inflammatory response. One of the most noticeable aspects in this study is the strong correlation between the survivin and bcl 2 over expression in colorectal cancer in p53 independent manner. A similar association between survivin and bcl-2 was recorded also in neuroblastoma [22], gastric cancer [23], and breast cancer [24]. Unlike gastric cancer [23], there was no significant correlation between survivin expression and p53 abnormalities in colorectal cancer. Both survivin and bcl-2 genes are similarly regulated by TATA-less and GC-rich promoter sequence [25]. However, regardless of the pathway of simultaneous co-expression, survivin and bcl-2 have different and non-overlapping anti-apoptosis mechanisms. Moreover, unlike bcl2, survivin was undetectable in normal adult tissues but abundantly expressed in transformed cell types and a variety of human cancers in vivo [25].

\section{Conclusion}

This study reports that $12-18 \mathrm{~nm}$ sized biogenic AgNPs have been successfully synthesized using honey bee extract as a novel reducing agent. Both the obtained AgNPs and their capping biomolecules showed anti-colon cancer activities at both cellular and molecular levels comparing with $5 \mathrm{FU}$. In conclusion, the single-step and ecofriendly synthesized AgNPs could be a promising agent in colon cancer therapy or drug delivery.

\section{Acknowledgement}

We sincerely thank Dr. Saad El Masry the researcher in Plant Protection and Biomolecular diagnosis Department, Arid Lands Cultivation Research Institute, City of Scientific Research and Technology Applications, for kindly providing of honey been workers.

\section{References}

1. Sriram MI, Barath S, Kanth M, Kalishwaralal K, Gurunathan S (2010) Antitumor activity of silver nanoparticles in Dalton's lymphoma ascites tumor model. Int J Nanomed 5: 753-762. 
Citation: El-Deeb NM, El-Sherbiny IM, El-Aassara MR, Hafez EE (2015) Novel Trend in Colon Cancer Therapy Using Silver Nanoparticles Synthesized by Honey Bee. J Nanomed Nanotechnol 6: 265. doi:10.4172/2157-7439.1000265

2. Asha Rani PV, Prakash Hande M, Valiyaveettil S (2009) Anti-proliferative activity of silver nanoparticles. BMC Cell Biology 10:65

3. Kasthuri J, Kathiravan K, Rajendiran N (2009) Phyllanthin-assisted biosynthesis of silver and gold nanoparticles: a novel biological approach. J Nanopart Res 11: 1075.

4. Sathishkumar M, Sneha K, Won SW, Cho CW, Kim S, et al. (2009) Cinnamon zeylanicum bark extract and powder mediated green synthesis of nanocrystalline silver particles and its bactericidal activity. Colloid Surf.B 73: 332 338

5. Philip D (2009) Biosynthesis of $\mathrm{Au}, \mathrm{Ag}$ and $\mathrm{Au}-\mathrm{Ag}$ nanoparticles using edible mushroom extract. SpectrochimActa A 73: 374-381.

6. Mendoza-Reséndez R, nunez NO, and Luna C (2012) Green Synthesis of Silver Nanoparticles Mediated by Bee Products, 13 th edition of trends in nanotechnology international conferecnce.

7. Ahmed M, Karns M, M. Goodson J, Rowe S, Hussain et al. (2008) DNA damage response to different surface chemistry of silver nanoparticles in mammalian cells. Toxicology and Applied Pharmacology 233: 404.

8. Yezhelyev MV, Gao X, Xing Y, Al-Hajj A, Nie S (2006) Emerging use of nanoparticles in diagnosis and treatment of breast cancer. Lancet Oncol: 657667.

9. Kim E, Kuk K, Yu J, Kim S, Park H, et al. (2007) Antimicrobial effects of silver nanoparticles. Nanomedicine: 3-95.

10. Lohr HF, Goergen B, Meyer zumBuschenfelde KH, Gerken G (1995) HCV replication in mononuclear cells stimulates anti- HCV-secreting $B$ cells and reflects nonresponsiveness to interferon-alpha. J Med Virol 46: 314-20.

11. Borenfreund E, Puerner JA (1985) Toxicity determined in vitro by morphological alterations and neutral red absorption. J Toxicol Lett 24: 119-124.

12. Nanji A, Zhao S, Sadrzadeh S, Waxman D (1994) Use of reverse transcriptasePCR to evaluate in vivo cytokine gene expression in chronic ethanol-fed rats. Hepatology 19: 1483-1487.

13. Viuda-Martos M, Ruiz-Navajas Y, FernIndez-oopez, Pérez-llvarez (2008) Functional properties of honey, propolis, and royal jelly. Journal of Food Science 73: R117.
14. Narayanan K, Sakthivel (2008) Coriander leaf mediated biosynthesis of gold nanoparticlesMater. Lett 62: 4588-4590.

15. Huang J, Li Q, Sun D, Lu Y, Su Y (2007) Biosynthesis of silver and gold nanoparticles by novel sundried Cinnamomum camphora leaf. Chen, Nanotechnology 18: 105104-105114.

16. Vedpriya A (2010) living systems: eco-friendly nanofactories. Dig J Nanomater Bios 5: 9-21

17. Murugaraj J, Manoharan R, Renganathan A, Davoodbasha M, Gnanasekar S, et al. (2013) An Investigation on the cytotoxicity and caspase-mediated apoptotic of biologically synthesized silver nanoparticles using Podophyllumhexandrum on human cervicalcarcinomacells effect. Colloids and Surfaces B: Biointerfaces $102: 708-717$.

18. Jeyaraj M, Sathishkumar G, Sivanandhan G, Mubarak Ali D, Rajesh M, et al. (2013) Biogenic silver nanoparticles for cancer treatment: an experimenta report. Colloids Surf B 106: 86-92.

19. Gurunathan S, Jegadeesh R, Sri Nurestri AM, Priscilla AJ, Vikineswary S (2013) Green synthesis of silver nanoparticles using Ganoderma neojaponicumlmazeki: a potential cytotoxic agent against breast cancer cellsInt. J. Nanomedicine 8: 4399-4413.

20. Park MVDZ, Neigh AM, Vermeulen JP (2011) The effect of particle size on the cytotoxicity, inflammation, developmental toxicity and genotoxicity of silver nanoparticles. Biomaterials 32: 9810-9817.

21. Molina MAF, Gamboa EM, Rivera CAS, Flores RAG, Zapata-Benavides P, et al. (2010) Antitumor activity of colloidal silver on MCF-7 human breast cancer cells. Padilla J Exp Clin Cancer Res 29: 148

22. Adida C, Berrebi D, Peuchmaur M, Reyes-Mugica M, Altieri DC (1998) Antiapoptosisgene, survivin and prognosis of neuroblastoma. Lancet 351: 882883.

23. Lu CD, Altieri DC, Tanigawa N (1998) Expression of a novel antiapoptosis gene, surviving, correlated with tumor cell apoptosis and p53 accumulation in gastric carcinomas. Cancer Res 58: 1808-1812.

24. Keitaro T, Shinji I, Goki G (2000) Expression of survivin and Its Relationship to Loss of Apoptosis in Breast Carcinomas. Clin Cancer Res 6: 127-134.

25. Ambrosini G, Adida C, Altieri DC (1997) A novel anti-apoptosis gene, survivin, expressed in cancer and lymphoma. Nat Med: 917-921. 